\title{
PSO BASED TUNING OF FUZZY LOGIC CONTROLLER FOR TWO AREA INTERCONNECTED POWER SYSTEM
}

\author{
H.A. Khattab, G.A. Morsy ${ }^{1}$ \\ Electrical Engineering Department \\ Faculty of Engineering, \\ Menoufiya University, Egypt
}

\author{
N. S. Nassar ${ }^{2}$ \\ Qaliobia Company of water \\ and wastewater
}

\begin{abstract}
:-
This paper proposes the use of particular swarm optimiaztion technique for optimizing input scaling factors for fuzzy logic controller of a two-area interconnected power system. The proposed approach has superior feature including easy implementation, stable convergence characteristics and very good computational performances efficiency. The main objective is to obtain a stable and robust controlled system by tuning the fuzzy logic controller gains (acting as the secondary controller in the AGC system) using PSO algorithm to achieve the lowest error function. Firstly, the interconnected two area power system is modeled and simulated using MATLAB-SIMLINK. The simulation results are obtained in compartive form with those obtained using other controllers like proportional-integral and fuzzy logic controllers to validate the effectiveness of the proposed fuzzy-swarm controller.

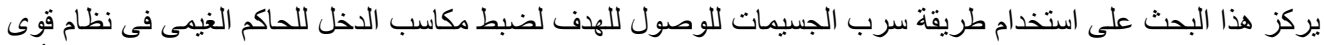

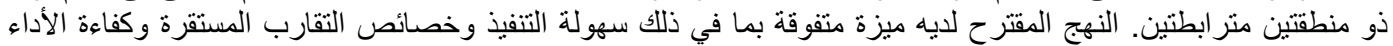

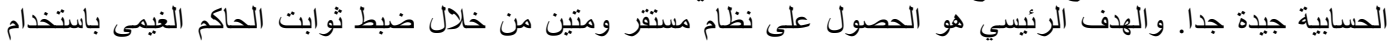

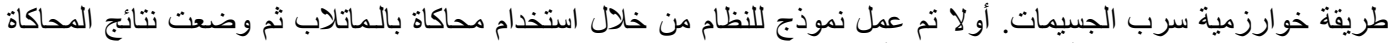

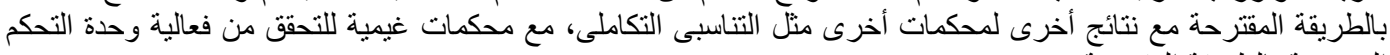
المصممة بالطريقة المقترحة.
\end{abstract}

Key-words: Automatic Generation Control (AGC), Proportional Integral (PI) Controller, Fuzzy logic controller (FLC), particle swarm Optimization (PSO), Load Frequency Control (LFC) and integral time absolute error (ITAE).

\section{Introduction}

Modern Power Systems with increasing electrical power demand are becoming more and more complicated. Therefore, it is required to produce the electrical power supply with stability and high reliability. Large interconnected power systems consist of interconnected control areas, which are connected through tie lines. Automatic Generation Control (AGC) or Load Frequency Control (LFC) is an important issue in power system operation and control for supplying stable and reliable electric power with good quality [1]. The main objectives of AGC for a power system include ensuring zero steady-state errors for frequency deviations, minimizing unscheduled tie line power flows between neighboring control areas and minimizing the effect of load disturbances [2]. Therefore, a control strategy is needed to keep the system frequency and inter-area tie-power flow as near to the scheduled values as possible. Among the various types of load frequency controllers, the most widely employed is the conventional proportional integral
(PI) controller. It is easier but usually gives large settling time.

In recent years, fuzzy system applications have received increasing attention in power system operation and control. Fuzzy logic based controllers have been suggested as an appropriate choice to control non-linear system and are being investigated as an alternative to conventional control [3]. Furthermore, the fuzzy logic controller (FLC) is a sophisticated

technique that is easy to design and implement [4]. The success of such controllers depends on proper selection of fuzzy inputs and the proper design of controller's gains. Nevertheless, the determination of membership functions and control rules is an inevitable problem in a design.

Particle Swarm Optimization is one of the most recent and powerful optimization techniques that finds the best parameters for controller in the uncertainty area of controller parameters [5]. Particle Swarm Optimization algorithm has been used in 
almost all sectors of industry and science. One of them is the load frequency control [6].

The objective of this paper is to investigate the load frequency control and inter area tie-power control problem for a two-area power system. An optimal control scheme based particle swarm optimization (PSO) algorithm is used for tuning the input scaling factors of FLC. The two area interconnected power system with the proposed controller is simulated with Matlab. The proposed controller is simulated for a two-area power system. The simulations were performed in order to show the effectiveness of the proposed controller over conventional PI and Fuzzy logic controller.

\section{Two Area Power System}

The studied power system contains two interconnected areas each consists of generator, turbine and governor with feedback of regulation constant. The block diagram of this two area power system is shown in Fig. (1), where $\Delta \mathrm{F}_{1}$ and $\Delta \mathrm{F}_{2}$ are the frequency deviations in area 1 and area 2 respectively in $\mathrm{Hz}$.

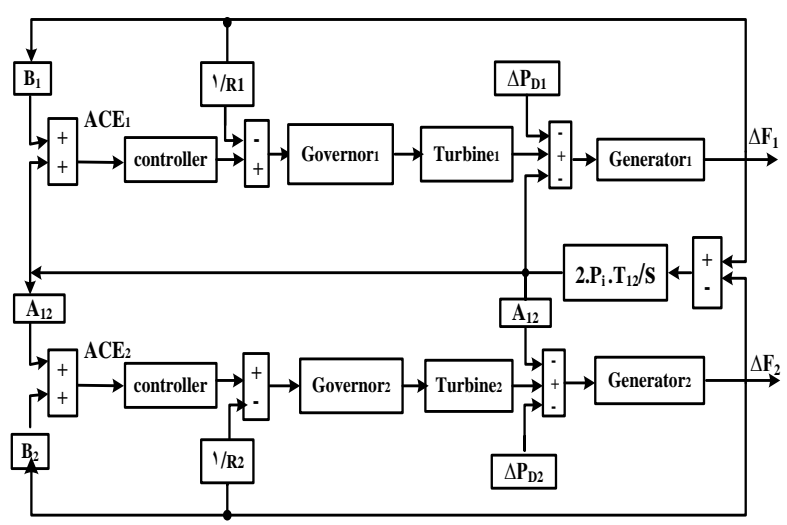

Fig. (1) Block diagram of two-area thermal system.

$\Delta \mathrm{P}_{\mathrm{D} 1}$ and $\Delta \mathrm{P}_{\mathrm{D} 2}$ are the change in load demand of area 1 and area 2 respectively $\left(\Delta \mathrm{P}_{\mathrm{D} 1}=\Delta \mathrm{P}_{\mathrm{D} 2}=1 \%\right.$ nominal demand). Detailed models are used in this study to obtain accurate results [7].

\section{Conventional Integral Controller}

The task of load frequency controller is to generate a control signal $U$ that maintains system frequency and tie-line interchange power at predetermined values [3]. The block diagram of PI controller is shown in Fig. (2). the control input $U_{i}$ is constructed as follows:

$\mathrm{U}_{\mathrm{i}}=-\mathrm{K}_{\mathrm{i}} \int(\mathrm{ACEi}) \mathrm{dt}+\mathrm{k}_{\mathrm{p}} \mathrm{ACE}_{\mathrm{i}}$

Thus the formula is:

$\mathrm{U}_{\mathrm{i}}=-\mathrm{K}_{\mathrm{i}} \int\left(\Delta \mathrm{P}_{\mathrm{Tie}, \mathrm{i}}+\beta_{\mathrm{i}} \Delta \mathrm{F}_{\mathrm{i}}\right) \mathrm{dt}+\mathrm{k}_{\mathrm{p}} \mathrm{ACE}_{\mathrm{i}}$

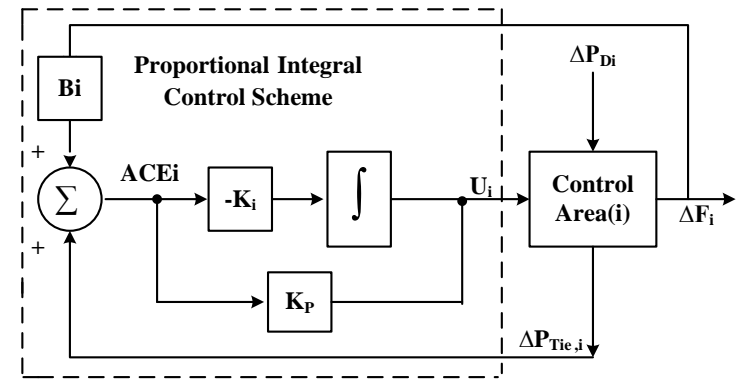

Fig. (2): Conventional PI Controller Installed on ith Area

Fixed gain controller designed at nominal operating conditions is failed to provide best control performance over wide range of operating conditions. It is simple for implementation but takes more time and gives large frequency deviation.

\section{Fuzzy Logic Controller}

Since power system, dynamic characteristics are complex and variable, conventional control methods cannot provide desired results [8]. The fuzzy logic control has tried to handle the robustness, reliability and nonlinearities associated with power system controls. Therefore, a fuzzy logic controller (FLC) becomes nonlinear and adaptive in nature having a robust performance under parameter variations with the ability to get desired control actions for complex uncertain, and nonlinear systems without their mathematical models and parameter estimation [9]. The fuzzy logic controller has two input signals, namely $\mathrm{ACE}$ and $\mathrm{ACE}^{\circ}$ and then the output signal is used for controlling the LFC in the interconnected power system.

There are three principal elements to a fuzzy logic controller:

- Fuzzification module (Fuzzifier).

- Rule base and inference engine.

- Defuzzification module (Defuzzifier).

Table-1 below shows the control rules. Triangular membership functions are used for both the inputs and output as shown in Fig. (3). This work proposes a fuzzy logic controller including 25 rules with 5membership functions.

Table (1): Control rules for FLC.

\begin{tabular}{|c|c|c|c|c|c|c|}
\hline \multicolumn{7}{|c|}{ ACE } \\
\hline \multirow{2}{*}{} & & NB & NS & ZE & PS & PB \\
\cline { 2 - 7 } & NB & NB & NB & NS & NS & ZE \\
\cline { 2 - 7 } & NS & NB & NB & NS & ZE & ZE \\
\cline { 2 - 7 } \multirow{2}{*}{} & ZE & NS & NS & ZE & PS & PS \\
\cline { 2 - 7 } & PS & ZE & PS & PS & PB & PB \\
\cline { 2 - 7 } & PB & ZE & ZE & PS & PB & PB \\
\hline
\end{tabular}

NB: negative big, NS: negative small, ZE: zero, PS: positive big, PB: positive small 


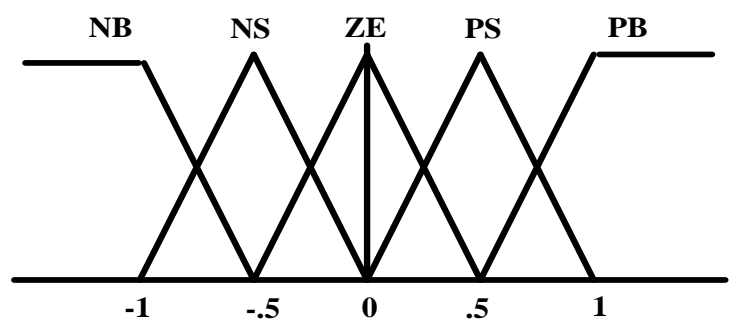

Fig. (3) Membership function for the FLC

Finally, resultant fuzzy subsets representing the controller output are converted to the crisp values using the central of area (COA) defuzzifier scheme. The overall Simulink model of two-area power system with fuzzy logic control is shown in Fig. (4).

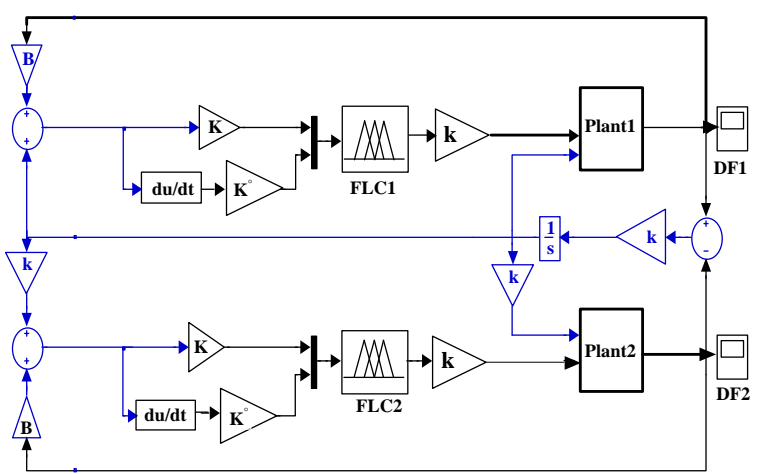

Fig. (4) Simulink model of two areas with FLC

\section{Review of Particle Swarm Optimization}

Particle Swarm Optimization introduced by Eberhart and Kennedy inspired by the movement behavior of bird and fish flocks. Swarm represents a number of potential solutions to the problem and the individual in PSO algorithm is called particle which mean search individual in search space can be adjusted dynamically based on the movement of position and velocity. Position and velocity of particle represent for the candidate solution to the problem and flying direction of the particle respectively [1]. With a given fitness function, the particle's position can be found with the best evaluation. To evaluate the best particle's position, two 'best' values namely pbest and gbest are updated. Thus, based on these two 'best' values, the position of particle can be adjusted by changing its velocity dynamically toward the global optimum. The basic formulas for updated position and velocity of each particle can be calculated as shown in equation 3 and 4.

$\mathrm{V}_{\mathrm{i}}^{\mathbf{k}+1}=\mathrm{W}_{*} \mathrm{~V}_{\mathrm{i}}^{\mathbf{k}}+\mathrm{C}_{1 *} \mathrm{R}_{1 *}\left(\right.$ Pbest $\left._{\mathbf{i}}-\mathrm{X}_{\mathrm{i}}\right)+\mathrm{C}_{2} * \mathrm{R}_{\mathbf{2}} *\left(\right.$ gbest $\left._{\mathrm{i}}-\mathrm{X}_{\mathrm{i}}\right)$ (3)
$\mathrm{X}_{\mathrm{i}}^{\mathrm{k}+1}=\mathrm{X}_{\mathrm{i}}^{\mathrm{k}}+\mathrm{V}_{\mathrm{i}}^{\mathrm{k}+1}$

Where $\mathrm{w}$ is inertia weight parameter, $\mathrm{C}_{1}, \mathrm{C}_{2}$ are weight factors, $v_{i k}$ is velocity of particle $i$ in $k_{\text {th }}$ iteration, $\mathrm{X}_{\mathrm{ik}}$ is position of particle $\mathrm{i}$ in kth iteration $, \mathrm{R}_{1}, \mathrm{R}_{2}$ are random number between 0 and gbest $=$ gbest of the group and Pbesti $=$ Pbest of particle $\mathrm{i}$ [2,5]. Fig. (5) Shows the flowchart of pso algorithm. The PSO algorithm parameters are shown in appendix II.

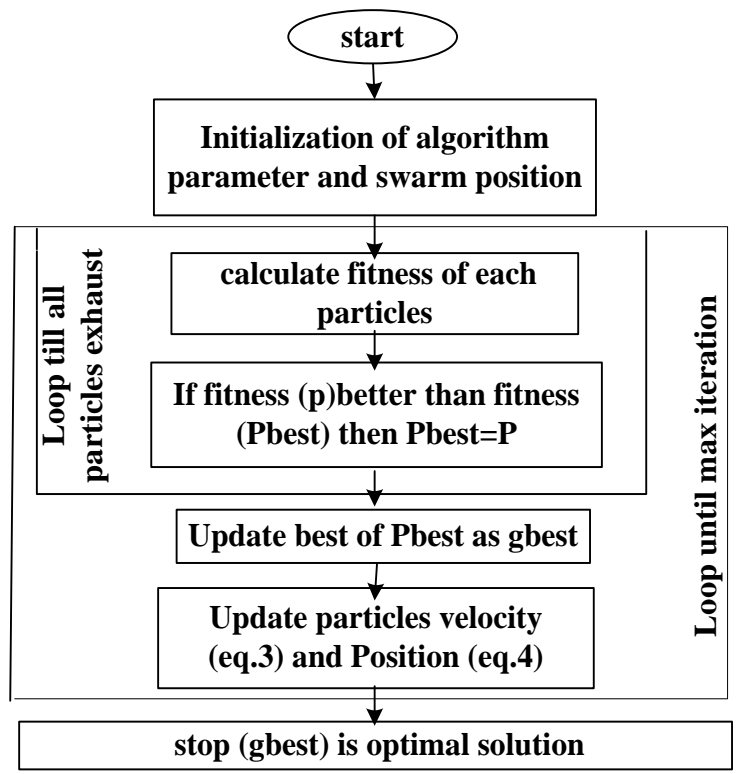

Fig. (5) Flowchart of PSO algorithm

\section{Design of Input Scaling Factors of FLC Using PSO}

The input scaling factors of fuzzy controller tuning by PSO is shown in Fig. (6). In this study the optimum values of the input fuzzy controller parameters, which minimize the error function, are accurately computed using particle swarm optimization [10].

In a typical run of the PSO, an initial population of random solutions is generated. Each particle keeps track of its coordinates in hyperspace, which are associated with the fittest solution it has achieved so far. The value of the error function, $\mathrm{P}_{1}$ is also stored. Another best value is also tracked. The global version of the PSO keeps track of the overall best value, and its location, obtained thus far by any particle in the population, which is called $\mathrm{Pg}$. the PSO, at each step, changes the velocity and the position of each particles toward its, $\mathrm{P}_{1}$ and $\mathrm{P}_{\mathrm{g}}[11]$.

The application of PSO involves repetitively performing two steps: 
1. The calculation of the error function for each of the particles in the current population. To do this, the system must be simulated to obtain the value of the objective function.

2. The particle swarm optimization then updates the particle coordinates based on equation (3) and (4).

These two steps are repeated from population to population until a stoping criterion terminates the search producing the optimum gains [12].

The error function considered in this study is ITAE of the form:

$$
\text { Minimize } J=\int t \stackrel{\infty}{t}\left(\left|\Delta \mathrm{P}_{\text {tie }}\right|+\left|\Delta \mathrm{F}_{\mathrm{i}}\right|\right) d t
$$

To compute the optimum controller gains, a unit-step load change is assumed at both areas.

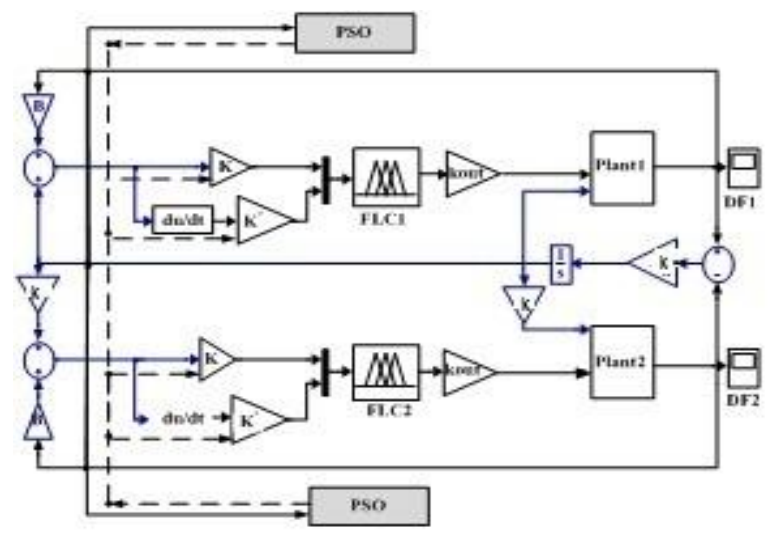

Fig. (6) Block Digram of FLC system with PSO

\section{Simulation Results}

The simulations were performed using the conventional PI, FLC and the proposed fuzzy swarm controllers applied to a two area interconnected power system is shown in Fig. 1 by applying 0.01 p.u MW step load disturbance to both areas. The system parameters are given in the Appendix I. The simulation was carried on a digital computer using a sampling interval of $t=0.01 \mathrm{sec}$. Table (2) tabulates the optimized values of input scaling factors of FLC using PSO.

Table (2): Optimized values of input scaling factors of FLC using PSO

\begin{tabular}{|c|c|l|l|}
\hline & $\begin{array}{c}1 \% \text { change in } \\
\text { load demand }\end{array}$ & $\mathrm{K}$ & $\mathrm{K}^{\circ}$ \\
\hline $\begin{array}{c}\text { Controller } \\
\text { Parameters } \\
\text { Optimized } \\
\text { by pso }\end{array}$ & $\begin{array}{c}\text { First Thermal } \\
\text { Area }\end{array}$ & 7.8 & 0.4899 \\
\cline { 2 - 4 } & $\begin{array}{c}\text { Second } \\
\text { Thermal Area }\end{array}$ & 0.1002 & 0.079 \\
\hline
\end{tabular}

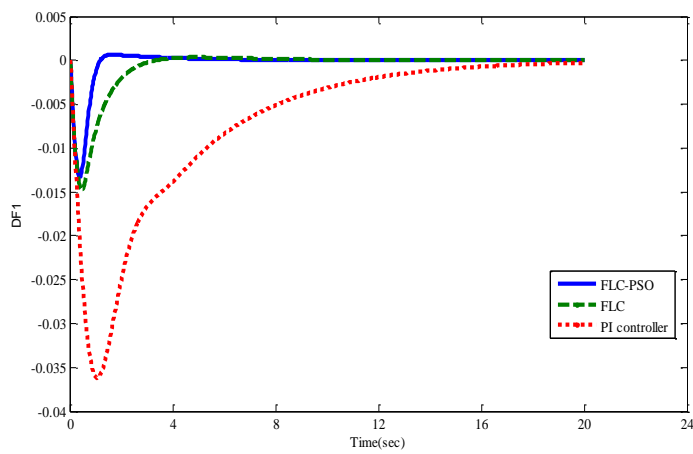

Fig. (7) Dynamic response for frequency deviation of area1

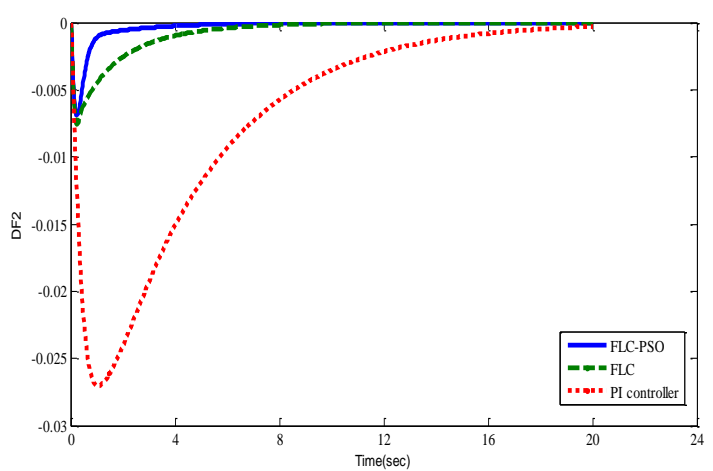

Fig. (8) Dynamic response for frequency deviation of area 2

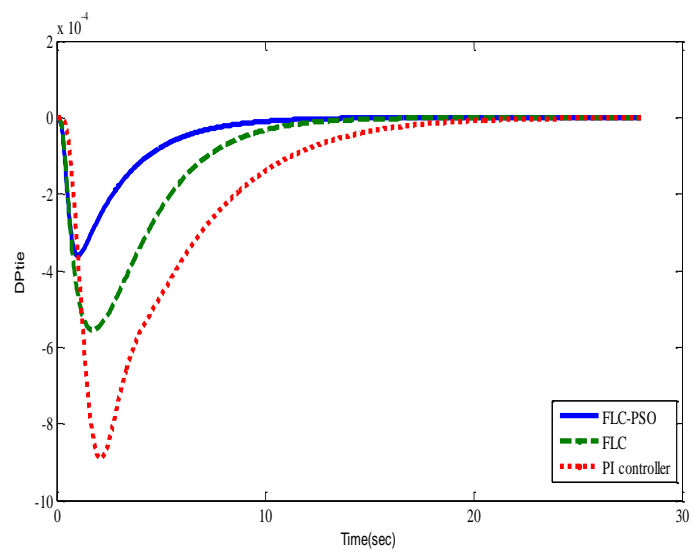

Fig. (9) Tie-line power deviation

Figs. $(7,8)$ show the frequency response of area 1, 2 for Fuzzy-PSO controller compared to conventional fuzzy controller and the PI controller. Fig. (9) shows the response of tie-line power for Fuzzy-PSO controller compared to conventional fuzzy controller and the PI controller. It is very clear that The FLC highly improves the system performance comparison to the conventional PI controller. Moreover, the proposed Fuzzy-PSO controller is significantly superior to the conventional PI controller and FLC in terms of fast recovery with less overshoot and less settling time Also, the tie-line power deviations are nearly stable (i.e. Less oscillation). 


\section{Conclusions}

In this study, a new particle swarm optimized fuzzy logic controller has been investigated for automatic load frequency control of a two area power system to damp out the frequency deviations and also to keep the tie line power at the scheduled value. It is shown that using the proposed controller there is a substantial improvement in the time domain specification in terms of lesser rise time, peak time, settling time as well as a lower overshoot compared with using the PI controller or fuzzy logic controller. Therefore, the proposed PSO-fuzzy controller is recommended for use in power system control. In addition, the proposed controller is simple and easy to implement since it does not require many information about system parameters.

\section{Appendix I}

System parameters are as follows: $\mathrm{F}=60 \mathrm{~Hz}, \mathrm{R}_{1}=$ $2.4 \mathrm{~Hz} /$ p.u $\mathrm{MW}, \mathrm{R}_{2}=2.2 \mathrm{~Hz} /$ p.u $\mathrm{MW}, \mathrm{T}_{\mathrm{g} 1}=.08 \mathrm{sec}$, $\mathrm{T}_{\mathrm{g} 2}=.05 \mathrm{sec}, \mathrm{T}_{\mathrm{t} 1}=.3 \mathrm{sec}, \mathrm{T}_{12}=.1 \mathrm{sec}, \mathrm{T}_{\mathrm{p} 1}=20 \mathrm{sec}$, $\mathrm{T}_{\mathrm{p} 2}=13 \mathrm{sec}, \mathrm{K}_{\mathrm{p} 1}=120 \mathrm{~Hz} /$ p.u $\mathrm{MW}, \mathrm{K}_{\mathrm{p} 2}=80, \mathrm{~Hz} /$ p.u $\mathrm{MW}, \mathrm{A}_{12}=-1$.

\section{APPENDIX II}

PSO parameters used in the present study:

Number of particles $=20, C_{1}=4.0, C_{2}=4, W=0.9$

\section{References:}

[1] K. RamaSudha, V.S.Vakula, Vijay a Shanthi," PSO based design of robust controller for two area load frequency control without linearities ", International Journal of Engineering Science and Technology, ISSN: 0975-5462, Vol. 2(5), 13111324, 2010.

[2] M. S. Yousuf, H. N.Al-Duwaish, Z. M. Al Hamouz, "PSO based Single and Two Interconnected Area Predictive Automatic Generation Control, " WSEAS Transactions on systems and control, ISSN: 1991-8763, Issue 8, Volume 5, August 2010.

[3] K. A. Ellithy, K.A. El-Metwally," Design of Decentralized Fuzzy Logic Load Frequency Controller," I.J. Intelligent Systems and Applications, 2012, 2, 66-75. DOI: 10.5815/ijisa.2012.02.08

[4] S. Pothiya, I. Ngamroo, S. Runggeratigul and P. Tanta swadi," Design of Optimal Fuzzy Logic based PI Controller using Multiple Tabu Search Algorithm for Load Frequency Control", international Journal of Control, Automation, and Systems, vol. 4, no. 2, pp. 155-164, April 2006.

[5] Neha Modi, Amol Barve, Kanchan Chaturvedi ,Particle Swarm Optimization based Load Frequency Control in Two Area Power System,"
International Journal on Emerging Technologies 4(1): 132-138, ISSN No. : 0975-8364, 2013.

[6] Ranuva, P.Rama, "PSO based tuning of PID controller for a Load frequency control in two area power system," IJERA, Vol. 1, Issue 3, pp. 1499-1505.

[7] Fosha C.E., Elgerd O.I.," the megawatt frequency control theory," IEEE Trans power APPI.Syst, Vol.89, pp.563-571, 1970.

[8] G. Panda, S. Panda and C. Ardil, "Automatic Generation Control of Interconnected Power System with Generation Rate Constraints by Hybrid Neuro Fuzzy Approach," International Journal of Electrical and Electronics Engineering 3:9, 2009.

[9] N.N.Shah, A.D.Chafekar, D.N.Mehta, A.R. Suthar,"Automatic load frequency control of two area power system with conventional and fuzzy logic control," IJERA, Vol. 1 , ISSN: 2319 1163, pp.343-347, November 2012.

[10]S. Prakash, S. Sinha, A. S. Pandey and B. Singh, "Impact of slider gain on load frequency control using Fuzzy Logic Controller, "ARPN Journal of Engineering and Applied Sciences, ISSN 18196608,VOL. 4, NO. 7, SEPTEMBER 2009.

[11] A. Ikhe, A. Kulkarni, Veeresh, "Load Frequency Control Using Fuzzy Logic Controller of Two Area thermal-thermal Power System," 2250-2459, Volume 2, Issue 10, IJETAE, October 2012.

[12] Atul Ikhe, Anant Kulkarni," Load frequency control for interconnected power system using different controllers," Automation, Control and Intelligent Systems; 1(4): 85-89, 2013. 